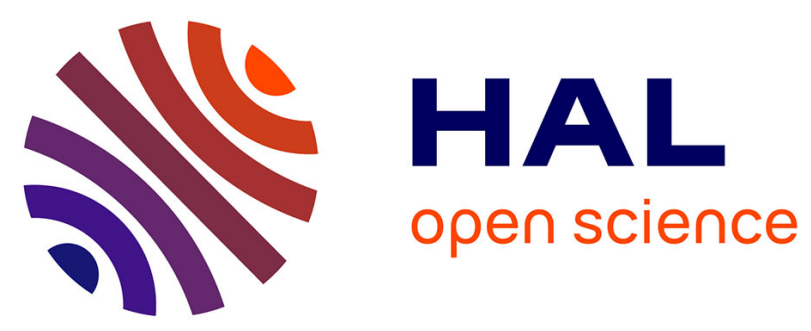

\title{
Higher plasma oxidative damage and lower plasma antioxidant defences in an Arctic seabird exposed to perfluoroalkyl carboxylic acids
}

David Costantini, Pierre Blévin, Dorte Herzke, Borge Moe, Geir Wing Gabrielsen, Jan Ove Bustnes, Olivier Chastel

\section{To cite this version:}

David Costantini, Pierre Blévin, Dorte Herzke, Borge Moe, Geir Wing Gabrielsen, et al.. Higher plasma oxidative damage and lower plasma antioxidant defences in an Arctic seabird exposed to perfluoroalkyl carboxylic acids. Environmental Research, 2019, 168, pp.278-285. 10.1016/j.envres.2018.10.003 . hal-02238536

\section{HAL Id: hal-02238536 \\ https://hal.science/hal-02238536}

Submitted on 26 Sep 2019

HAL is a multi-disciplinary open access archive for the deposit and dissemination of scientific research documents, whether they are published or not. The documents may come from teaching and research institutions in France or abroad, or from public or private research centers.
L'archive ouverte pluridisciplinaire HAL, est destinée au dépôt et à la diffusion de documents scientifiques de niveau recherche, publiés ou non, émanant des établissements d'enseignement et de recherche français ou étrangers, des laboratoires publics ou privés. 
1 Higher plasma oxidative damage and lower plasma antioxidant defences in an

4 David Costantini ${ }^{1, *}$, Pierre Blévin ${ }^{2}$, Dorte Herzke ${ }^{3}$, Børge Moe ${ }^{4}$, Geir Wing Gabrielsen ${ }^{5}$, Jan Ove Bustnes ${ }^{6}$ and Olivier Chastel ${ }^{2}$

6

71 UMR 7221 CNRS/MNHN, Muséum National d'Histoire Naturelle, Sorbonne 8 Universités, 7 rue Cuvier 75005 Paris, France

$9 \quad{ }^{2}$ Centre d'Etudes Biologiques de Chizé (CEBC), UMR 7372 - CNRS Université de La 10 Rochelle, 79360 Villiers-en-Bois, France

$11{ }^{3}$ Norwegian Institute for Air Research, NILU, Fram Centre, NO-9296 Troms $\varnothing$, Norway

124 Norwegian Institute for Nature Research, NINA, Høgskoleringen 9, NO-7034

13 Trondheim, Norway

$14 \quad{ }^{5}$ Norwegian Polar Institute, Fram Centre, NO-9296 Troms $\varnothing$, Norway

$15{ }^{6}$ Norwegian Institute for Nature Research, NINA, Fram Centre, NO-9296 Troms $\varnothing$, 16 Norway

* Corresponding author:

19 David Costantini

UMR 7221 CNRS/MNHN

Muséum National d'Histoire Naturelle

7 rue Cuvier 75005 Paris

23 France

24 email david.costantini@mnhn.fr

25 Tel. : +33(0)1.40.79.53.74 
ABSTRACT

27 Perfluoroalkyl and polyfluoroalkyl substances (PFASs) may cause detrimental effects on physiological function and reproduction of Arctic animals. However, there is a paucity of information on the link between PFASs and oxidative stress, which can have potential detrimental effects on key fitness traits, such as cellular homeostasis or reproduction. We have examined the correlations between multiple blood-based markers of oxidative status and several perfluoroalkyl carboxylic acids (i.e., with 8 or more carbons) in male Arctic black-legged kittiwakes (Rissa tridactyla) during the pre-laying period. Higher protein oxidative damage was found in those birds having higher concentrations of perfluorododecanoic acid (PFDoA), perfluorotridecanoic acid (PFTriA) and perfluorotetradecanoic acid (PFTeA). Lower plasmatic non-enzymatic micro-molecular antioxidants was found in those birds having higher concentrations of perfluoroundecanoic acid (PFUnA), PFDoA and PFTeA. Effect size estimates showed that the significant correlations between PFASs and oxidative status markers were intermediate to strong. The non-enzymatic antioxidant capacity (including antioxidants of protein origin) was significantly lower in those birds having higher plasma concentration of linear perfluorooctanesulfonic acid (PFOSlin) only. In contrast, the activity of the antioxidant enzyme glutathione peroxidase in erythrocytes was not associated with any PFAS compounds. Our results suggest that increased oxidative stress might be one consequence of long-chain PFAS contamination. Given the correlative nature of our study, experimental work will be needed to demonstrate whether PFASs cause toxic effects on free-living vertebrates through increased oxidative stress. 
INTRODUCTION

Ecotoxicological studies have so far extensively directed their attention toward legacy persistent organic pollutants (POPs) like organochlorine pesticides (OCPs) and polychlorobiphenyls (PCBs). ${ }^{1}$ In contrast, less attention has been given to the environmental toxicity of other organic contaminants in the Arctic, such as chlorinated paraffins, phthalates, siloxanes or the perfluoroalkyl and polyfluoroalkyl substances (PFASs). ${ }^{2}$ Among these, PFASs remain comparatively much less investigated. ${ }^{3}$ PFASs are synthetically manufactured chemicals, produced since the $1950 \mathrm{~s}$, that are widely used for numerous industrial and commercial purposes as water repellents and surfactants (e.g., impregnation agents for carpets, papers and textiles, fire-fighting foam, non-stick coating and waterproof clothing). ${ }^{4-5}$ Chemically and thermally stable, PFASs are highly persistent in the environment and have been detected globally in both wildlife and humans. ${ }^{6-8}$ Because of oceanic currents and atmospheric long-range transport, PFASs and their precursors and breakdown products can reach high latitudes, such as the Arctic Ocean. ${ }^{9-}$

11 Once deposited in the Arctic marine ecosystem, PFASs bio-accumulate in living organisms and bio-magnify along the food webs. ${ }^{12-16}$ Importantly, (i) PFASs have long half-lives, which facilitates their bio-accumulation through the food webs depending on the species and PFAS congener ${ }^{8}$; (ii) the long and odd carbon-chain-length PFASs appear to be more bio-accumulative and toxic than the short and even-chain length PFASs in wildlife. ${ }^{17-20}$

It is worthwhile to note that while PFASs have been produced for over 50 years, it is only since late 1990s that their occurrence in the environment has come under scientific scrutiny. PFASs have raised recent concerns about their potential physiological disrupting properties and negative impacts on reproductive fitness in wildlife (multiple 
species in ${ }^{21}$; lesser black-backed gull in ${ }^{22}$; northern fulmar in ${ }^{23}$; zebrafish in ${ }^{24}$; tree swallow in ${ }^{25}$; black-legged kittiwake and northern fulmar in ${ }^{26}$; black-legged kittiwake in ${ }^{27-28}$; black-legged kittiwake in ${ }^{29-30}$; glaucous gull in ${ }^{31}$; common eider, black guillemot, black-legged kittiwake, glaucous gull, arctic skua and great skua in ${ }^{32}$ ).

Increased molecular oxidative damage and disruption of antioxidant defences are suspected as important mechanisms through which PFASs could be detrimental for cell function and, possibly, for organism health. Experimental evidence on laboratory models found that PFASs may increase production of reactive oxygen species (ROS), increase molecular oxidative damage and up- or down-regulate antioxidant defences. ${ }^{24,33-34}$ Further work found that the perfluoroundecanoic and perfluorododecanoic acids (PFUnA and PFDoA, respectively) are equally potent inducers of stress response genes relative to perfluorooctane sulfonic acid (PFOS) and perfluorononanoic acid (PFNA) and that the effect of carbon-chain-length was more important than the functional group in determining oxidative stress. ${ }^{35}$ There is thus good reason to expect that long-chain PFASs might cause dysregulation of the oxidative homeostasis, leading to accumulation of oxidative damage to key biomolecules like proteins or nucleic acids. However, the effect of PFAS exposure on oxidative stress is almost unknown for wildlife. To the best of our knowledge, only two studies have addressed this topic in free-living animals. ${ }^{36}$ did not find any significant relationship between plasma PFAS concentrations and the activity of the antioxidant enzyme superoxide dismutase in plasma of white-tailed eagle nestlings, while ${ }^{32}$ did not find any significant relationship between PFASs and amount of DNA damage in lymphocytes.

Long-lived species, like many polar seabirds that occupy high trophic levels, are exposed to a greater risk of accumulation and sensitivity to high concentrations of 
contaminants. In Svalbard (European Arctic), a number of studies showed that blacklegged kittiwakes (Rissa tridactyla, hereafter "kittiwake") are chronically exposed to a complex cocktail of organic contaminants and trace elements, which are known to correlate with physiological metrics, impaired individual fitness and population associated with markers of oxidative damage and antioxidant protection.

In this study, we have examined the correlations between blood-based markers of oxidative status and several PFAS compounds in male kittiwakes during the pre-laying oxidative status marker and each PFAS compound varies according to their carbon-chainlength $\left(\mathrm{C}_{8-14}\right)$ because the toxicity of PFASs may increase with carbon-chain-length. period, while controlling for a number of potential confounding factors that might affect the oxidative status independently from PFASs (i.e., body condition, body size, both time and day of blood sampling, hormonal status; reviewed in ${ }^{40}$ ). As with the hormonal status, we measured plasma levels of testosterone, baseline corticosterone and luteinizing hormone because prior work found large individual variation among kittiwakes ${ }^{27-28,38}$ and significant effects on organism's oxidative status ${ }^{40}$, which could affect the relationships between PFAS and oxidative status markers. We focused on males because this investigation on oxidative stress is part of a larger project aiming at assessing the overall consequences (ornament coloration, fecundity, oxidative stress, sexual hormones) of PFASs exposure in males during the pre-laying stage (nest site defence, pair-bonding, copulation, nest building) a period during which males appear to be sensitive to pollutants. $^{38}$

We have also examined whether the effect size of the association between each 


\section{MATERIALS AND METHODS}

\section{Sampling}

123 Fieldwork was conducted in 2016 on a colony of Arctic kittiwakes at Kongsfjord (78 54'

$\left.124 \mathrm{~N} ; 12^{\circ} 13^{\prime} \mathrm{E}\right)$, Svalbard. Blood samples were collected from 50 adult males during the 125 pre-laying period (courtship and mating period), from $25^{\text {th }}$ May to $6^{\text {th }}$ June. Birds were caught on their nest with a loop at the end of a long pole. Within 3 minutes since capture $0.5 \mathrm{ml}$ of blood were taken from the brachial vein using a heparinized syringe and a $25-$ gauge needle. This blood sample was used to measure oxidative status markers and hormones. Straightaway, a second sample of venous blood (ca. $2 \mathrm{ml}$ ) was collected using another syringe and this blood sample was used to assess the PFASs burden. Then, tarsus, skull (head + bill) and wing length were measured using a calliper (nearest $0.1 \mathrm{~mm}$ ) and body mass was taken using a Pesola spring balance (nearest 5 grams). Blood samples were stored on ice in the field. On average, blood samples were stored on ice for 3h40min 38s (min: 1h30; $\max 9 \mathrm{~h} 55)$ before being centrifuged and stored at $-80^{\circ} \mathrm{C}$. Plasma and red blood cells, obtained after centrifugation, were kept frozen separately, either at $-80^{\circ} \mathrm{C}$ for subsequent oxidative status markers or at $-20^{\circ} \mathrm{C}$ for PFAS analyses. All samples were analysed within 4 months since collection.

\section{Hormone assays}

140 Plasma levels of testosterone, baseline corticosterone and luteinizing hormone (LH) were measured by radioimmunoassay at the Centre d'Etudes Biologiques de Chizé following protocols previously validated. Briefly, testosterone and corticosterone were extracted using diethyl ether and ethyl ether, respectively. Plasma concentrations of all three hormones were measured by radioimmunoassay. As with corticosterone, a commercial 
antiserum against corticosterone-3-(O-carboxy- methyl) oxime bovine serum albumin conjugate (Biogenesis, UK) was used. The lowest detectable quantities significantly different from zero at a $90 \%$ confidence level were $0.05 \mathrm{ng} / \mathrm{ml}$ for testosterone, $0.4 \mathrm{ng} / \mathrm{ml}$ for corticosterone and $1.7 \mathrm{ng} / \mathrm{ml}$ for LH. All samples were analysed in duplicate. Corticosterone and LH were analysed in a single run and the mean coefficient of variation was 4.9 and $12.0 \%$, respectively. Testosterone was analysed in two runs and the coefficients of variation were 11.2 and $11.5 \%$.

\section{Oxidative status markers}

154 One marker of plasma oxidative damage, one marker of plasma non-enzymatic antioxidant capacity and one red blood cell antioxidant enzyme were measured at the Centre d'Etudes Biologiques de Chizé using standard methods. Protein carbonyls (marker of oxidative protein damage) were measured using the Protein Carbonyl Colorimetric assay (Cayman Chemical Company, Ann Arbor, USA). This assay is based on the colorimetric method proposed by ${ }^{41}$. A same volume of plasma was used for all samples and the amount of carbonyls was standardised by the plasma protein concentration according to manufacturer's instructions. Protein carbonyls were derivatized to 2,4dinitrophenylhydrazone by reaction with 2,4-dinitrophenylhydrazine (DNPH). The absorbance was read at $370 \mathrm{~nm}$. The extinction coefficient for DNPH $(0.022 / \mu \mathrm{M} / \mathrm{cm})$ was used to calculate the concentration of protein carbonyls, which was expressed as $\mathrm{nmol} / \mathrm{mg}$ protein (amount of carbonyls generated per unit of protein) or as total nmol obtained by multiplying the concentration of carbonyls by the concentration of plasma proteins (i.e., total amount of carbonyls in the sample, which is also dependent on the amount of substrates available, i.e., proteins). The mean coefficient of variation of duplicates was 
$11.5 \%$. The metric expressed as $\mathrm{nmol} / \mathrm{mg}$ indicates the amount of carbonyls that occurs in a same amount of protein, thus this is standardised by the amount of substrates (i.e.,

171 proteins) that can be carbonylated. The second metric expressed as total amount of 172 carbonyls indicates the total amount of carbonyls that occurs in the tissue, which is 173 influenced by the amount of proteins available. This second metric is also important 174 because accumulation of carbonyls is detrimental for the cells ${ }^{50}$. The OXY-Adsorbent test 175 (Diacron International, Italy) was used to quantify the non-enzymatic antioxidant capacity of plasma against $\mathrm{HOCl}$. Values were expressed as either $\mathrm{mM}$ of $\mathrm{HOCl}$ 177 neutralised or as $\mathrm{mM}$ of $\mathrm{HOCl}$ neutralised/mg protein to estimate the antioxidant potential 178 of micromolecular antioxidants (e.g., vitamins, carotenoids, glutathione) without the contribution of proteins (i.e., non-enzymatic micro-molecular antioxidant capacity). The correlation between OXY values and protein concentration was actually high and significant $(\mathrm{r}=0.76, \mathrm{p}<0.001)$, which is to be expected because plasma proteins, such as albumin, are prone to react with $\mathrm{HOCl}$. Although free-radical trapping properties vary among proteins, standardising OXY values by the concentration of total plasma proteins gave us some kind of control about the contribution of proteins to OXY. The mean coefficient of variation of duplicates was 9.4\%. The Ransel assay (RANDOX Laboratories, UK) was used to measure the activity of the antioxidant enzyme glutathione peroxidase (GPX) in haemolysates (red blood cells diluted with distilled water). Values were expressed as Units of GPX/mg of protein of haemolysate. The mean coefficient of variation of duplicates was $8.1 \%$. The Bradford protein assay (Bio-Rad Laboratories, Hercules, USA) with bovine albumin as a reference standard was used to measure the concentration of proteins in both plasma samples and haemolysates. 


\section{PFAS analyses}

194

195

Perfluoroalkyl carboxylic acids (i.e., PFASs with 8 or more carbons) were analysed in plasma at the Norwegian Institute for Air Research (NILU) in Troms $\emptyset$, Norway. The following compounds were analysed in each plasma sample: perfluorooctanesulfonamide (PFOSA), perfluorobutanesulfonic acid (PFBS), perfluoropropanesulfonic acid (PFPS), perfluorohexanesulfonic acid (PFHxS), perfluoroheptanesulfonic acid (PFHpS), perfluorooctane sulfonic acid (PFOSlin), branched perfluorooctane sulfonic acid (PFOSbr), perfluorononane sulfonic acid (PFNS), perfluorodecane sulfonic acid (PFDcS), perfluorohexanoic acid (PFHxA), perfluoroheptanoic acid (PFHpA), perfluorooctanoic acid (PFOA), perfluorononanoic acid (PFNA), perfluorodecanoate (PFDcA), perfluoroundecanoic acid (PFUnA), perfluorododecanoic acid (PFDoA), perfluorotridecanoic acid (PFTriA), perfluorotetradecanoic acid (PFTeA) and two precursor compounds, the fluorotelomer sulfonates (6:2 FTS and 8:2 FTS). PFASs with concentrations below the limit of quantification (LOQ) were replaced with a value equal to $(\mathrm{LOQ} \times$ detection frequency) when the detection frequency (percentage of detection) was > 50\%. A $0.2 \mathrm{ml}$ aliquot of plasma spiked with internal standards (carbon labeled PFAS $)^{42}$ was extracted in methanol $(1 \mathrm{ml})$ by repeated sonication and vortexing. The supernatant was cleaned-up using ENVICarb graphitized carbon absorbent and glacial acetic acid. Extracts were analysed by UPLC/MS/MS. Recovery of the internal standards ranged between $86.3 \%$ and $120 \%$. Results were validated with blanks (clean and empty glass tubes treated like a sample) and standard reference material (1957 human serum from NIST) run with every 10 samples. The deviation of the target concentrations in the SRMs were within the laboratory's accepted range (69-119\%). Blanks varied between 
concentrations below the instrument detection limits and $30 \mathrm{pg} / \mathrm{g}$ and were applied as the

217 LOD in the form of 3 times the average concentration.

\section{Body size and body condition}

220 A body size index was estimated using the PC1 from a PCA of tarsus, skull and wing length (loadings, $0.73,0.83$ and 0.45 , respectively). As far as the body condition, we did not use the ratio of body mass onto body size nor the residuals of a linear regression of body mass onto body size because both indices have been criticized. ${ }^{43}$ Rather we included both body mass and body size index as factors in the models. In doing so, the coefficient estimate of body mass is calculated considering the effect of body size, thus the outcome reflects the effect of body condition on the given marker of oxidative status. ${ }^{43}$

\section{Statistical analyses}

229

Generalized linear models were performed using the software STATISTICA 10 (StatSoft. Inc., Tulsa, OK, USA) to assess relationships between each oxidative status marker (protein carbonylation, non-enzymatic antioxidant capacity, non-enzymatic micro-molecular antioxidant capacity and glutathione peroxidase) and the following predictor variables: PFASs congener (PFOSlin, PFNA, PFDcA, PFUnA, PFDoA, PFTriA or PFTeA), body size index, body mass, hormonal status, day of blood sampling and time of blood sampling. All predictor variables were scaled to mean of 0 and standard deviation of 1 . These predictor variables were included in all models because prior work showed that each of them can be significantly associated with oxidative status markers (reviewed in ${ }^{40}$ ). The two metrics of protein oxidative damage (protein carbonyls per mg of protein and total protein carbonyls) were combined using the PC1 from a Principal Components 
240 Analysis (PCA) because they were highly correlated $(r=0.79, p<0.001)$. The hormonal 241 status was estimated using the PC1 from a PCA of corticosterone, testosterone and 242 luteinizing hormone (loadings, 0.39, 0.61 and 0.84 , respectively). A normal error function 243 and an identity-link function were applied to models of non-enzymatic antioxidant 244 capacity and GPX. A gamma error function and an identity-link function were applied to models of protein carbonyls and non-enzymatic micro-molecular antioxidant capacity. These functions were selected because the model had the best fitting to the dataset according to the Akaike Information Criterion. Preliminary analyses showed that the time elapsed from the collection of blood to its storage was not significantly correlated (pvalue $>0.45$ ) with any marker of oxidative status nor hormones, thus it was not further considered in the analyses. Visual inspection of residuals, Q-Q plots and Cook's distance did not highlight any violation of normality and homogeneity of variance nor the presence of outliers (all samples were below a 0.5 Cook's distance). The variance inflation factor was always below 2, indicating that multicollinearity was low. The multicollinearity is thought to be high and problematic when the variance inflation factor is higher than 5 . size Hedges' g from test statistics of oxidative status markers that had significant associations with PFASs (i.e., protein oxidative damage and non-enzymatic micromolecular antioxidant capacity). The "forestplots function" of the "metafor package" in $\mathrm{R}$ was used to visualise boxplots of effect size and $95 \%$ confidence interval. Effect sizes were considered to be small (Hedges' $\mathrm{g}=0.2$, explaining $1 \%$ of the variance), intermediate $(\mathrm{g}=0.5$, explaining $9 \%$ of the variance) or large $(\mathrm{g}=0.8$, explaining $25 \%$ of the variance) according to ${ }^{46}$. 


\section{RESULTS}

Concentrations of detectable PFASs are reported in Table 1 together with other variables measured in kittiwakes. Six out of 20 PFASs (i.e. PFOSlin, PFNA, PFDcA, PFUnA, PFDoA, PFTriA) were detectable in all individuals, while one PFAS (i.e. PFTeA) was detectable in 33 out of 50 individuals. PFOSlin, PFUnA and PFTriA concentrations were the highest of all PFASs measured in the investigated samples, with a percentage contribution for each kittiwake ranging from 23.4 to $54.5 \%$, from 20.3 to $34.8 \%$ and from 11.8 to $35.2 \%$, respectively. The percentage contribution of all other detected PFASs ranged between 0.1 and 10.6\%. PFOSA, PFBS, PFPS, PFHxS, PFHpS, PFOSbr, PFNS, PFDcS, PFHxA, PFHpA, PFOA, and the two precursor fluorotelomer sulfonates (6:2 FTS and 8:2 FTS) were below the detection limit in all the investigated samples.

Protein oxidative damage was significantly higher in those birds having higher plasma concentration of PFDoA, PFTriA or PFTeA (Table 2). Effect size estimates increased with chain length of PFASs (indicating an increase of protein damage with chain length) and were significantly different from zero ) for PFDoA (95\% confidence interval: 0.06 to 1.25 ), PFTriA (95\% confidence interval: 0.01 to 1.20$)$ and PFTeA (95\% confidence interval: 0.29 to 1.54;Fig. 1). The non-enzymatic micro-molecular antioxidant capacity was significantly lower in those birds having higher plasma concentration of PFUnA, PFDoA or PFTeA (Table 2). There was also a near-significance tendency of the non-enzymatic micro-molecular antioxidant capacity to be lower in birds with higher plasma PFTriA (Table 2). Effect size estimates were larger for longer PFASs (indicating a decrease of micro-molecular antioxidants with chain length) and were significantly different from zero for PFUnA (95\% confidence interval: -1.20 to -0.02 ), PFDoA (95\% 
Fig. 2). The non-enzymatic antioxidant capacity including the contribution of antioxidant of protein origin was significantly lower in those birds having higher plasma concentration of PFOSlin, but it was not associated with any other PFAS congener (Table 2). The activity of GPX was not associated with any PFAS compounds (Table 2).

Finally, our models showed that (i) kittiwakes in poorer body condition had more plasma protein carbonyls, (ii) the non-enzymatic antioxidant capacity was higher in kittiwakes sampled later in the day, and (iii) the non-enzymatic micro-molecular antioxidant capacity was higher in kittiwakes having lower concentrations of hormones.

\section{DISCUSSION}

Our results provide the first evidence in wild vertebrates that the correlation between oxidative status markers and PFASs is stronger for long-chain congeners. We found that male kittiwakes having higher plasma concentrations of long-chain PFASs had more protein oxidative damage and less plasma antioxidants after controlling statistically for potentially confounding variables. The non-enzymatic antioxidant capacity (including antioxidants of protein origin) was significantly lower in kittiwakes having higher plasma concentration of PFOSlin. On the other hand, the activity of glutathione peroxidase in erythrocytes was not related to any PFAS congener. Effect size estimates were intermediate to large, indicating that PFASs explained from 9 to more than $25 \%$ of the variance in protein oxidative damage and non-enzymatic micro-molecular antioxidant capacity of plasma. ${ }^{46}$ Intermediate effect sizes are suggested to be biologically meaningful because average proportions of variance explained in ecological, evolutionary and physiological studies is usually below $7 \% .{ }^{47}$ Our effect size estimates were also larger 
than those found in the comparison of oxidative status markers between animals living in polluted (e.g., air pollution, heavy metals) and unpolluted sites. ${ }^{48}$

PFOSlin, PFUnA and PFTrA concentrations were the highest of all PFASs measured in the investigated samples, with a percentage contribution for each kittiwake ranging from 11.8 to $54.5 \%$. The concentration of PFOSlin was higher than that previously recorded in males from the same kittiwake population in 2012 (13.4 vs. 10.6 $\left.\mathrm{pg} / \mathrm{g} \mathrm{ww} \mathrm{in}^{29}\right)$. In contrast, the average concentrations of PFUnA (10.3 vs. $12.1 \mathrm{pg} / \mathrm{g} \mathrm{ww}$ $\mathrm{in}^{29}$ ) and of PFTrA (8.6 vs. $11.6 \mathrm{pg} / \mathrm{g} \mathrm{ww}$ in $^{29}$ ) were both lower in our study than in prior work. $^{29}$ One reason for such differences might be because ${ }^{29}$ measured PFASs of male kittiwakes caught during the chick rearing phase. Work on male glaucous gulls during the incubation period in Svalbard found levels of PFOSlin similar to ours, while those of PFUnA (4.4 pg/g ww) and of PFTrA (3.9 pg/g ww) were much lower than those we recorded..$^{31}$

The strength of the correlation between oxidative status markers and PFASs increased with the chain length of the congener. While persistent in the environment, PFASs with fewer than eight carbons, such as PFHxA, and PFSAs with fewer than six carbons, such as PFBS, are generally less toxic and bioaccumulative in wildlife and humans, while exposure of laboratory animals to long-chain congeners produces detrimental reproductive, developmental, and systemic effects. ${ }^{4,6,18,49}$ For example, the toxic effects of PFASs on rat brain cells decreased with increasing carbon chain length. ${ }^{17}$ Interestingly, the toxic effects of PFASs were attenuated by the antioxidant vitamin E, indicating a possible involvement of oxidative stress in the reduction of cell viability. ${ }^{49}$ Further work showed that, compared to short-chain PFASs, long-chain PFASs are stronger inducers of the response of genes regulating the cell oxidative status. ${ }^{35}$ 

in laboratory models and almost unexplored in wild animals. Thus, limited information is available for a comparison with our results and interpretation. Protein carbonylation arises from overproduction of ROS by metabolic reactions that use oxygen and shift the balance between oxidant/antioxidant statuses in favour of the oxidants. ${ }^{50}$ Protein carbonylation also occurs when carbonyls are introduced into proteins through the reactions with lipid oxidative damage products (malondialdehyde and hydroxynonenal). ${ }^{50}$

Carbonylation is mostly irreversible and results in alteration of protein structure and function. Only a small fraction of carbonylated proteins can be removed through proteasome-dependent proteolysis. Work carried out on laboratory models found evidence that exposure to PFASs may change expression of genes regulating proteasome activation and proteolysis. ${ }^{6,51-52}$ It is, however, unclear, whether such changes in gene expression make proteins one important target of the pro-oxidant effects of PFASs. This is important because when protein carbonyls accumulate, they tend to aggregate leading to cell death, tissue injury and development of disorders. Several studies found higher amounts of plasma protein carbonyls in individuals affected by a given disease, ${ }^{53-54}$ suggesting a potential role of protein carbonylation in disease progression. oxidation due to reaction with ROS, reduced intake from diet or mobilisation of antioxidants from blood to other target tissues. Irrespective of the reason, prior work on other bird species found evidence that circulating antioxidants may be linked to important individual or population fitness-related traits. For example, ${ }^{55}$ found that barn swallows (Hirundo rustica) with lower plasma non-enzymatic antioxidants had reduced probability of survival. ${ }^{56}$ found that Gentoo (Pygoscelis papua) and Adélie (Pygoscelis adeliae) 
penguins from increasing populations had higher plasma non-enzymatic antioxidant capacity than those from decreasing populations.

Metabolic activity is one important source of ROS production. Thus the association we found between PFASs and oxidative status markers might mirror an effect of PFASs on metabolism. Prior work on the same kittiwake population found a positive association between the long-chain PFTriA and resting metabolic rate in females but not in males. ${ }^{30}$ Thus, the association between PFASs and oxidative status markers does not appear, at least for males, to be due to a dysregulation of general body metabolism. The lack of an effect on metabolic rate does not reject the hypothesis that ROS production might have been higher in the more contaminated birds. For example, PFASs might have localised effects on important ROS generators (e.g., mitochondria of red blood cells or of other target tissues) without compromising the metabolism of the whole organism. In vitro studies found that PFAS exposure may impair mitochondrial activity and lead to increased rates of ROS production. ${ }^{57}$

It is unclear why the activity of glutathione peroxidase was not associated with any PFAS compound. It might be that up-regulation of this enzyme might have been too costly for the birds given the imminent start of breeding activity or that any effects of PFASs on oxidative status did not come through the pathways involving glutathione peroxidase. The biochemical function of glutathione peroxidase is to reduce hydrogen peroxide to water and organic hydroperoxides to their corresponding alcohols. ${ }^{50}$ Thus, we cannot exclude that results would have been different if another antioxidant enzyme with a different biochemical function would have been measured. There are, however, many discrepancies in the literature about the response of antioxidant enzymes to PFAS exposure. For example, prior work did not find any association between PFASs exposure 
and whole-body catalase activity in the planktonic crustacean Daphnia magna ${ }^{58}$ or plasma superoxide dismutase activity in white-tailed eagle (Haliaeetus albicilla) nestlings. ${ }^{36}$ In contrast, exposure to PFASs affected catalase activity in hepatocytes of freshwater tilapia Oreochromis niloticus ${ }^{24}$ and expression of antioxidant genes Sod1, Sod2, Gpx2 and Nqo1 in mouse pancreas. ${ }^{59}$ Irrespective of the mechanisms involved, the activity of GPX in erythrocytes does not appear to be an informative marker about the impact on oxidative status of the PFASs we have measured in this work.

In conclusion, our work shows that higher protein oxidative damage was found in those birds having higher concentrations of PFDoA, PFTriA and PFTeA. Lower plasmatic non-enzymatic micro-molecular antioxidants was found in those birds having higher concentrations of PFUnA, PFDoA and PFTeA. Experimental work will be needed to ascertain whether the correlation between individual PFAS burden and oxidative status markers reflects a direct toxic effect of PFASs on oxidative homeostasis. It will also be important to determine whether increased oxidative damage or decreased antioxidant defences turn into a reduction in survival probability or lifetime reproductive success. Resistance against oxidative stress may also decrease with chronological age. ${ }^{60}$ Thus, we highlight the importance of assessing in future studies whether the effects of PFASs on oxidative status markers are stronger in older individuals.

\section{ACKNOWLEDGEMENTS}

This project was financially and logistically supported by Institut Polaire Français (IPEV project 330 to O. Chastel) and by Research Council of Norway (RCN, Arctic Field Grant $\mathrm{n}^{\circ} 256934$ from the Research Council of Norway provided to P. Blévin). P. Blévin was funded by a PhD grant from University of La Rochelle. Additional funding was provided 
407

408

409

410

411

412

413

414

415

416

417

418

419

420

421

422

423

424

425

426

427

428

429

430

by the Hazardous Substances Flagship (the Multistress project) at the Fram center in Troms $\varnothing$ and by the Contrat de Plan État-Région (CPER) ECONAT, at the CEBC. We thank the Polar Norwegian institute for their logistic help in the field. We also thank the Littoral Environnement et Sociétés (Université La Rochelle) for allowing us to use the plate reader to measure one of the markers. This study was approved by the Norwegian Food Safety Authority (FOTS ID 8679) and the Governor of Svalbard. We thank Ségolène Humann-Guilleminot, Bruno Michaud, Solveig Nilsen and Ingrid Gabrielsen for their great help in the field. We thank all the staff of the NILU for their assistance during PFASs analysis; C. Trouvé and C. Parenteau from CEBC for hormone assay. Finally, we thank four anonymous reviewers for providing their comments on our work.

\section{COMPETING INTERESTS}

The authors declare no competing financial interests.

\section{REFERENCES}

(1). Stockholm Convention. Stockholm convention on persistent organic pollutants. Geneva, Switzerland: Stockholm Convention Secretariat 2009; Available from: http://chm.pops.int/Convention/ThePOPs/tabid/673/language/en-US/Default.aspx.

(2). AMAP. Chemicals of emerging Arctic concern. Summary for Policy-makers. Arctic Monitoring and Assessment Programme (AMAP), Oslo, Norway, 2017.

(3). DeWitt, J. C. Toxicological effects of perfluoroalkyl and polyfluoroalkyl substances. Humana Press, 2015.

(4). Jensen, A. A.; Leffers, H. Emerging endocrine disrupters: perfluoroalkylated substances. Int. J. Androl. 2008, 31, 161-169. 
431 (5). Kissa, E. Fluorinated Surfactants and Repellents. Second ed. Marcel Dekker, 432 New York, 2001.

433 (6). Lau, C.; Anitole, K.; Hodes, C.; Lai, D.; Pfahles-Hutchens, A.; Seed, J. 434 Perfluoroalkyl acids: a review of monitoring and toxicological findings. Toxicol. Sci. $4352007,99,366-394$.

436 (7). Key, B. D.; Howell, R. D.; Criddle, C. S. Fluorinated organics in the biosphere. 437 Environ. Sci. Technol. 1997, 31, 2445-2454.

438 (8). Muir, D. C.; de Wit, C. A. Trends of legacy and new persistent organic pollutants 439 in the circumpolar arctic: overview, conclusions, and recommendations. Sci. Total $440 \quad$ Environm. 2010, 408, 3044-3051.

441 (9). Butt, C. M.; Berger, U.; Bossi, R.; Tomy, G. T. Levels and trends of poly-and 442 perfluorinated compounds in the arctic environment. Sci. Total Environm. 2010, 408, 2936-2965.

444 (10). Giesy, J. P.; Kannan, K. Global distribution of perfluorooctane sulfonate in 445 wildlife. Environ. Sci. Technol. 2001, 35, 1339-1342.

446 (11). Prevedouros, K.; Cousins, I. T.; Buck, R. C.; Korzeniowski, S. H. Sources, fate 447 and transport of perfluorocarboxylates. Environ. Sci. Technol. 2006, 40, 32-44.

448 (12). Fang, S.; Chen, X.; Zhao, S.; Zhang, Y.; Jiang, W.; Yang, L.; Zhu, L. Trophic 449 magnification and isomer fractionation of perfluoroalkyl substances in the food web of 450 Taihu Lake, China. Environ. Sci. Technol. 2014, 48, 2173-2182.

451 (13). Haukås, M.; Berger, U.; Hop, H.; Gulliksen, B.; Gabrielsen, G. W. 452 Bioaccumulation of per-and polyfluorinated alkyl substances (PFAS) in selected species 453 from the Barents Sea food web. Environ. Pollut. 2007, 148, 360-371. 
(14). Kannan, K.; Tao, L.; Sinclair, E.; Pastva, S. D.; Jude, D. J.; Giesy, J. P. Perfluorinated compounds in aquatic organisms at various trophic levels in a Great Lakes food chain. Arch. Environ. Contam. Toxicol. 2005, 48, 559-566.

(15). Kelly, B. C.; Ikonomou, M. G.; Blair, J. D.; Surridge, B.; Hoover, D.; Grace, R.; Gobas, F. A. Perfluoroalkyl contaminants in an Arctic marine food web: trophic magnification and wildlife exposure. Environ. Sci. Technol. 2009, 43, 4037-4043.

(16). Tomy, G. T.; Budakowski, W.; Halldorson, T.; Helm, P. A.; Stern, G. A.; Friesen, K.; Pepper, K.; Tittlemier, S. A.; Fisk, A. T. Fluorinated organic compounds in an eastern Arctic marine food web. Environ. Sci. Technol. 2004, 38, 6475-6481.

(17). Berntsen, H. F.; Bjørklund, C. G.; Audinot, J. N.; Hofer, T.; Verhaegen, S.; Lentzen, E.; Gutleb, A. C.; Ropstad, E. Time-dependent effects of perfluorinated compounds on viability in cerebellar granule neurons: dependence on carbon chain length and functional group attached. Neurotoxicol. 2017, 63, 70-83.

(18). Conder, J. M.; Hoke, R. A.; de Wolf, W.; Russell, M. H.; Buck, R. C. Are PFCAs bioaccumulative? A critical review and comparison with regulatory criteria and persistent lipophilic compounds. Environ. Sci. Technol. 2008, 42, 995-1003.

(19). Martin, J. W.; Smithwick, M. M.; Braune, B. M.; Hoekstra, P. F.; Muir, D. C.; Mabury, S. A. 2004. Identification of long-chain perfluorinated acids in biota from the Canadian Arctic. Environ. Sci. Technol. 2004, 38, 373-380.

(20). Verreault, J.; Houde, M.; Gabrielsen, G. W.; Berger, U.; Haukås, M.; Letcher, R.J.; Muir, D. C. Perfluorinated alkyl substances in plasma, liver, brain, and eggs of glaucous gulls (Larus hyperboreus) from the Norwegian arctic. Environ. Sci. Technol. 2005, 39, 7439-7445. 
477 (21). Bossi, R.; Riget, F. F.; Dietz, R. ; Sonne, C. ; Fauser, P. ; Dam, M. ; Vorkamp, K. 478 Preliminary screening of perfluoroctane sulfonate (PFOS) and other fluorochemicals in 479 fish, birds and marine mammals from Greenland and the Faroe Islands. Environ. Pollut. $480 \quad 2005,136,323-329$.

481 (22). Bustnes, J. O.; Erikstad, K. E.; Lorentsen, S. H.; Herzke, D. Perfluorinated and 482 chlorinated pollutants as predictors of demographic parameters in an endangered seabird. Environ. Pollut. 2008, 156, 414-424.

484

(23). Braune, B. M.; Trudeau, S.; Jeffrey, D. A.; Mallory, M. L. Biomarker responses associated with halogenated organic contaminants in northern fulmars (Fulmarus glacialis) breeding in the Canadian Arctic. Environ. Pollut. 2011, 159, 2891-2898.

(24). Liu, Y.; Wang, J.; Fang, X.; Zhang, H.; Dai, J. 2011. The thyroid-disrupting effects of long-term perfluorononanoate exposure on zebrafish (Danio rerio). Ecotoxicol. 2011, 20, 47-55.

490

(25). Custer, C. M.; Custer, T. W.; Schoenfuss, H. L.; Poganski, B. H.; Solem, L. Exposure and effects of perfluoroalkyl compounds on tree swallows nesting at Lake Johanna in east central Minnesota, USA. Reprod. Toxicol. 2012, 33, 556-562.

(26). Nøst, T. H.; Helgason, L. B.; Harju, M.; Heimstad, E. S.; Gabrielsen, G. W.; Jenssen, B. M. Halogenated organic contaminants and their correlations with circulating thyroid hormones in developing Arctic seabirds. Sci. Total Environm. 2012, 414, 248256.

497 (27). Tartu, S.; Gabrielsen, G. W.; Blévin, P.; Ellis, H.; Bustnes, J. O.; Herzke, D.; 498 Chastel, O. Endocrine and fitness correlates of long-chain perfluorinated carboxylates 499 exposure in Arctic breeding black-legged kittiwakes. Environ. Sci. Technol. 2014a, 48, $13504-13510$. 
(28). Tartu, S.; Angelier, F.; Herzke, D.; Moe, B.; Bech, C.; Gabrielsen, G. W.; Bustnes, J. O.; Chastel, O. The stress of being contaminated? Adrenocortical function and reproduction in relation to persistent organic pollutants in female black legged kittiwakes. Sci. Tot. Environm. 2014b, 476-477, 553-560.

(29). Blévin, P.; Angelier, F.; Tartu, S.; Bustamante, P.; Herzke, D.; Moe, B.; Bech, C.; Gabrielsen, G. W.; Bustnes, J. O.; Chastel, O. 2017a. Perfluorinated substances and telomeres in an Arctic seabird: Cross-sectional and longitudinal approaches. Environ. Pollut. 2017a, 230, 360-367.

(30). Blévin, P.; Tartu, S.; Ellis, H. I.; Chastel, O.; Bustamante, P.; Parenteau, C.; Herzke, D.; Angelier, F.; Gabrielsen, G. W. Contaminants and energy expenditure in an Arctic seabird: Organochlorine pesticides and perfluoroalkyl substances are associated with metabolic rate in a contrasted manner. Environ. Res. 2017b, 157, 118-126.

(31). Melnes, M.; Gabrielsen, G. W.; Herzke, D.; Sagerup, K.; Jenssen, B. M. Dissimilar effects of organohalogenated compounds on thyroid hormones in glaucous gulls. Environ. Res. 2017, 158, 350-357.

(32). Haarr, A.; Hylland, K.; Eckbo, N.; Gabrielsen, G. W.; Herzke, D.; Bustnes, J. O.; Blévin, P.; Chastel, O.; Moe, B.; Hanssen, S. A.; Sagerup, K.; Borgå, K. DNA damage in Arctic seabirds: baseline, sensitivity to a genotoxic stressor, and association with organohalogen contaminants. Environ. Toxicol. Chem. 2018, 37, 1084-1091.

(33). Yao, X.; Zhong, L. Genotoxic risk and oxidative DNA damage in HepG2 cells exposed to perfluorooctanoic acid. Mutation Res./Genet. Toxicol. Environ. Mutag. 2005, 587, 38-44.

(34). Eriksen, K. T.; Raaschou-Nielsen, O.; Sorensen, M.; Roursgaard, M.; Loft, S.; Moller, P. Genotoxic potential of the perfluorinated chemicals PFOA, PFOS, PFBS, 
PFNA and PFHxA in human HepG2 cells. Mutation Res./Genet. Toxicol. Environ.

526

527

528

529

530

531

532

533

534

535

536

537

538

539

540

541

542

543

544

545

546

Mutag. 2010, 700, 39-43.

(35). Nobels, I. ; Dardenne, F. ; De Coen, W.; Blust, R. Application of a multiple endpoint bacterial reporter assay to evaluate toxicological relevant endpoints of perfluorinated compounds with different functional groups and varying chain length. Toxicol. In Vitro 2010, 24, 1768-1774.

(36). Sletten, S.; Bourgeon, S.; Bårdsen, B. J.; Herzke, D.; Criscuolo, F.; Massemin, S.; Zahn, S.; Johnsen, T. V.; Bustnes, J. O. Organohalogenated contaminants in white tailed eagle (Haliaeetus albicilla) nestlings: an assessment of relationships to immunoglobulin levels, telomeres and oxidative stress. Sci. Total Environ. 2016, 539, 337-349.

(37). Goutte, A.; Barbraud, C.; Herzke, D.; Bustamante, P.; Angelier, F.; Tartu, S.; Clément-Chastel, C.; Moe, B.; Bech, C.; Gabrielsen, G. W.; Bustnes, J. O.; Chastel, O. Survival rate and breeding outputs in a high Arctic seabird exposed to legacy persistent organic pollutants and mercury. Environ. Pollut. 2015, 200, 1-9.

(38). Tartu, S.; Goutte, A.; Bustamante, P.; Angelier, F.; Moe, B.; Clément-Chastel, C.; Bech, C.; Gabrielsen, G. W.; Bustnes, J. O.; Chastel, O. To breed or not to breed: Endocrine response to mercury contamination by an Arctic seabird. Biol. Lett. 2013, 9, 20130317.

(39). Blévin, P.; Angelier, F.; Tartu, S.; Ruault, S.; Bustamante, P.; Herzke, D.; Moe, B.; Bech, C.; Gabrielsen, G. W.; Bustnes, J. O.; Chastel, O. Exposure to oxychlordane is associated with shorter telomeres in arctic breeding kittiwakes. Sci. Total Environ. 2016, $563,125-130$. 
(40). Costantini, D. Oxidative stress and hormesis in evolutionary ecology and physiology: a marriage between mechanistic and evolutionary approaches. Springer-

549 Verlag, Berlin Heidelberg, pp. 348, 2014.

550 (41). Levine, R. L.; Garland, D.; Oliver, C. N.; Amici, A.; Climent, I.; Lenz, A. G.;

551 Ahn, B. W.; Shaltiel, S.; Stadtman, E. R. Determination of carbonyl content in oxidatively modified proteins. Methods Enzymol. 1990, 186, 464-478.

553

(42). Hanssen, L.; Dudarev, A. A.; Huber, S.; Odland, J. Ø.; Nieboer, E.; Sandanger, T.

M. Partition of perfluoroalkyl substances (PFASs) in whole blood and plasma, assessed in maternal and umbilical cord samples from inhabitants of arctic Russia and Uzbekistan. Sci. Total Environm. 2013, 447, 430-437.

557

(43). García-Berthou, E. On the misuse of residuals in ecology: testing regression 558 residuals vs. the analysis of covariance. J. Anim. Ecol. 2001, 70, 708-711.

(44). Del Re, A. C. Compute.es: compute effect sizes. R package version 0.2-2, 2013, http://cran.r-project.org/web/packages/compute.es.

(45). R Core Team, et al. R: A language and environment for statistical computing. $\mathrm{R}$

562 Foundation for Statistical Computing Vienna, Austria, 2013, https://www.R-project.org/

(46). Cohen, J. Power analysis for the behavioural sciences. Erlbaum, Hillsdale, 1988.

564

(47). Møller, A.; Jennions, M. D. How much variance can be explained by ecologists and evolutionary biologists? Oecologia 2002, 132, 492-500.

(48). Isaksson, C. Pollution and its impact on wild animals: a meta-analysis on 567 oxidative stress. EcoHealth 2010, 7, 342-350.

(49). Concawe. Environmental fate and effects of poly-and perfluoroalkyl substances (PFAS); 2016. Available online at https://www.concawe.eu/publications/ 
570 (50). Halliwell, B. H.; Gutteridge, J. M. C. Free Radicals in Biology and Medicine. 571 Oxford University Press, Oxford, 2015.

572 (51). Nilsen, A. J.; Landin, M. A.; Haug, K. H.; Fonnum, F.; Berger, U.; Osmundsen,

$573 \mathrm{H}$. Comparative hepatic gene expression profiling of rats treated with $1 \mathrm{H}, 1 \mathrm{H}, 2 \mathrm{H}, 2 \mathrm{H}-$ 574 heptadecafluorodecan-1-ol or with pentadecafluorooctanoic acid. Physiol Genom. 2008, $57534,285-303$.

576 (52). Zhang, W.; Liu, Y.; Zhang, H.; Dai, J. Proteomic analysis of male zebrafish livers 577 chronically exposed to perfluorononanoic acid. Environm. Int. 2012, 42, 20-30.

578 (53). Winterbourn, C. C.; Bonham, M. J.; Buss, H.; Abu-Zidan, F. M.; Windsor, J. A. 579 Elevated protein carbonyls as plasma markers of oxidative stress in acute pancreatitis. 580 Pancreatol. 2003, 3, 375-382.

581 (54). Hlaváčková, A.; Štikarová, J.; Pimková, K.; Chrastinová, L.; Májek, P.; Kotlín, 582 R.; Čermák, J.; Suttnar, J.; Dyr, J. E. Enhanced plasma protein carbonylation in patients 583 with myelodysplastic syndromes. Free Radic. Biol. Med. 2017, 8, 1-7.

584 (55). Saino, N.; Caprioli, M.; Romano, M.; Boncoraglio, G.; Rubolini, D.; Ambrosini, 585 R.; Bonisoli-Alquati, A.; Romano, A. Antioxidant defenses predict long-term survival in 586 a passerine bird. PLoS One 2011, 6, e19593.

587 (56). Beaulieu, M.; Thierry, A.-M.; González-Acuña, D.; Polito, M. J. Integrating 588 oxidative ecology into conservation physiology. Conserv. Physiol. 2013, 1, cot004.

589 (57). O'Brien, T. M.; Wallace, K. B. Mitochondrial permeability transition as the 590 critical target of N-acetyl perfluorooctane sulfonamide toxicity in vitro. Toxicol. Sci. 591 2004, 82, 333-340. 
592 (58). Li, M.-H. Chronic effects of perfluorooctane sulfonate and ammonium 593 perfluorooctanoate on biochemical parameters, survival and reproduction of Daphnia 594 magna. J. Health Sci. 2010, 56, 104-111.

595 (59). Kamendulis, L. M.; Wu, Q.; Sandusky, G. E.; Hocevar, B. A. Perfluorooactnoic 596 acid exposure triggers oxidative stress in the mouse pancreas. Toxicol. Rep. 2014, 1, 513597521.

598 (60). Marasco, V.; Stier, A.; Boner, W.; Griffiths, K.; Heidinger, B.; Monaghan, P. 599 Environmental conditions can modulate the links among oxidative stress, age, and 600 longevity. Mech. Ageing Dev. 2017, 164, 100-107.

601 

oxidative status markers (i.e., responde variables) and several individual metrics 604 (potential confounding factors) measured in 50 male black-legged kittiwakes from 605 Svalbard.

\begin{tabular}{|l|l|}
\hline Variable & $\begin{array}{l}\text { Mean } \pm \\
\text { Standard } \\
\text { deviation }\end{array}$ \\
\hline CONTAMINANT & \\
\hline PFOSlin - Linear perfluorooctane sulfonic acid (ng/g ww) & $13.4 \pm 6.2$ \\
\hline PFNA - Perfluorononanoic acid (ng/g ww) & $2.0 \pm 0.9$ \\
\hline PFDcA - Perfluorodecanoic acid (ng/g ww) & $2.9 \pm 1.2$ \\
\hline PFUnA - Perfluoroundecanoic acid (ng/g ww) & $10.3 \pm 3.7$ \\
\hline PFDoA - Perfluorododecanoic acid (ng/g ww) & $1.7 \pm 0.8$ \\
\hline PFTriA - Perfluorotridecanoic acid (ng/g ww) & $8.6 \pm 3.1$ \\
\hline PFTeA - Perfluorotetradecanoic acid (ng/g ww) & $1.0 \pm 0.8$ \\
\hline OXIDATIVE STATUS MARKERS - RESPONSE VARIABLES & \\
\hline Protein carbonyls (nmol/mg protein) & $1.8 \pm 0.6$ \\
\hline Total protein carbonyls (nmol) & $22.5 \pm 8.2$ \\
\hline Glutathione peroxidase (Units/mg protein) & $0.4 \pm 0.2$ \\
\hline Non-enzymatic antioxidant capacity (mM HOCl neutralised) & $169.9 \pm 37.1$ \\
\hline Non-enzymatic micro-molecular antioxidant capacity (mM HOCl neutralised/mg protein) & $13.0 \pm 2.0$ \\
\hline INDIVIDUAL TRAITS & \\
\hline Body mass (g) & $416.2 \pm 23.1$ \\
\hline Skull length (mm) & $93.9 \pm 1.6$ \\
\hline Tarsus length (mm) & $34.9 \pm 1.0$ \\
\hline Wing length (mm) & $317.1 \pm 6.3$ \\
\hline Baseline corticosterone (ng/ml) & $9.6 \pm 7.4$ \\
\hline Testosterone (ng/ml) & $1.7 \pm 1.4$ \\
\hline Luteinizing hormone (ng/ml) & $6.2 \pm 2.4$ \\
\hline
\end{tabular}


607 Table 2. The table shows the outcomes of generalized linear models performed to test the 608 effect of each PFASs congener on oxidative status markers. Each model also included a 609 number of potential confounding factors that may affect oxidative status markers 610 independently from PFASs. Significant effects are shown in bold type. Note that the 611 coefficient estimate for the relationship between body mass and the dependent variable 612 (i.e., oxidative status marker) is calculated considering the effect of body size, thus it 613 actually indicates the covariation between a given marker and the individual body 614 condition. ${ }^{43}$ GPX $=$ glutathione peroxidase; $\mathrm{N}-\mathrm{E}$ Antioxs $=$ non-enzymatic antioxidant 615 capacity of plasma; N-E Micromol Antioxs = non-enzymatic micro-molecular 616 antioxidant capacity of plasma; $c e \pm s e=$ coefficient estimate \pm standard error.

\begin{tabular}{|c|c|c|c|c|c|c|c|c|}
\hline & $\begin{array}{l}\text { Protein } \\
\text { Oxidative } \\
\text { Damage } \\
\end{array}$ & & GPX & & $\begin{array}{l}\mathrm{N}-\mathrm{E} \\
\text { Antioxs }\end{array}$ & & $\begin{array}{l}\mathrm{N}-\mathrm{E} \\
\text { Micromol } \\
\text { Antioxs } \\
\end{array}$ & \\
\hline $\begin{array}{l}\text { Main effect } \\
\text { included in the } \\
\text { model }\end{array}$ & $\mathrm{ce} \pm \mathrm{se}$ & $P$ & ce \pm se & $P$ & $\mathrm{ce} \pm \mathrm{se}$ & $\mathrm{P}$ & ce \pm se & $p$ \\
\hline PFOSlin & $0.03 \pm 0.12$ & 0.817 & $002+002$ & 0.462 & $-137+50$ & 0.006 & $-0.20+0.28$ & 0.484 \\
\hline sampling date & $0.11 \pm 0.13$ & 0.406 & $0.03 \pm 0.03$ & 0.309 & $-16.6 \pm 5.0$ & 0.001 & $0.18 \pm 0.31$ & 0.546 \\
\hline sampling time & $-0.20 \pm 0.11$ & 0.074 & $0.03 \pm 0.02$ & 0.196 & $14.3 \pm 4.6$ & 0.002 & $0.22 \pm 0.28$ & 0.425 \\
\hline body mass & $-0.29 \pm 0.12$ & 0.013 & $-0.02 \pm 0.03$ & 0.407 & $4.0 \pm 5.0$ & 0.424 & $0.00 \pm 0.29$ & 1.000 \\
\hline body size & $-0.02 \pm 0.11$ & 0.840 & $0.02 \pm 0.02$ & 0.403 & $-5.5 \pm 4.7$ & 0.236 & $0.10 \pm 0.27$ & 0.704 \\
\hline hormonal status & $-0.10 \pm 0.11$ & 0.391 & $0.02 \pm 0.02$ & 0.348 & $4.0 \pm 4.7$ & 0.391 & $-0.94 \pm 0.28$ & 0.001 \\
\hline PFNA & $-0.03+0.13$ & 0.852 & $0.01+0.03$ & 0.764 & $-1.0+6.0$ & 0.872 & $-0.09+0.34$ & 0.804 \\
\hline sampling date & $0.08 \pm 0.15$ & 0.580 & $0.02 \pm 0.03$ & 0.433 & $-10.7 \pm 6.0$ & 0.077 & $0.22 \pm 0.35$ & 0.534 \\
\hline sampling time & $-0.20 \pm 0.11$ & 0.074 & $0.03 \pm 0.02$ & 0.208 & $14.2 \pm 5.0$ & 0.004 & $0.22 \pm 0.28$ & 0.423 \\
\hline body mass & $-0.30 \pm 0.12$ & 0.011 & $-0.02 \pm 0.03$ & 0.395 & $5.2 \pm 5.4$ & 0.336 & $0.01 \pm 0.29$ & 0.977 \\
\hline body size & $-0.01 \pm 0.11$ & 0.896 & $0.02 \pm 0.02$ & 0.353 & $-7.4 \pm 5.0$ & 0.137 & $0.08 \pm 0.27$ & 0.768 \\
\hline hormonal status & $-0.08 \pm 0.11$ & 0.460 & $0.03 \pm 0.02$ & 0.262 & $0.28 \pm 4.9$ & 0.953 & $-0.98 \pm 0.27$ & $<0.001$ \\
\hline PFDcA & $0.22 \pm 0.13$ & 0.106 & $0.00 \pm 0.03$ & 0.904 & $-0.65 \pm 5.8$ & 0.910 & $-0.49 \pm 0.31$ & 0.116 \\
\hline sampling date & $0.22 \pm 0.14$ & 0.104 & $0.02 \pm 0.03$ & 0.493 & $-10.5 \pm 5.0$ & 0.075 & $-0.02 \pm 0.33$ & 0.950 \\
\hline sampling time & $-0.18 \pm 0.11$ & 0.088 & $0.03 \pm 0.02$ & 0.195 & $14.1 \pm 4.9$ & 0.004 & $0.21 \pm 0.27$ & 0.438 \\
\hline body mass & $-0.22 \pm 0.12$ & 0.056 & $-0.02 \pm 0.03$ & 0.407 & $5.1 \pm 5.6$ & 0.357 & $-0.07 \pm 0.29$ & 0.809 \\
\hline body size & $-0.03 \pm 0.11$ & 0.795 & $0.02 \pm 0.02$ & 0.352 & $-7.4 \pm 5.0$ & 0.140 & $0.09 \pm 0.27$ & 0.723 \\
\hline hormonal status & $-0.14 \pm 0.11$ & 0.204 & $0.03 \pm 0.02$ & 0.249 & $0.24 \pm 4.9$ & 0.960 & $-0.92 \pm 0.27$ & 0.001 \\
\hline sampling date & $0.19 \pm 0.14$ & 0.181 & $0.02 \pm 0.03$ & 0.517 & $-12.0 \pm 5.8$ & 0.038 & $-0.07 \pm 0.32$ & 0.822 \\
\hline sampling time & $-0.18 \pm 0.11$ & 0.098 & $0.03 \pm 0.02$ & 0.196 & $13.9 \pm 4.9$ & 0.005 & $0.19 \pm 0.27$ & 0.483 \\
\hline body mass & $-0.24 \pm 0.12$ & 0.045 & $-0.02 \pm 0.03$ & 0.403 & $4.2 \pm 5.7$ & 0.453 & $-0.13 \pm 0.29$ & 0.659 \\
\hline body size & $-0.03 \pm 0.11$ & 0.807 & $0.02 \pm 0.02$ & 0.348 & $-7.1 \pm 5.0$ & 0.154 & $0.12 \pm 0.26$ & 0.644 \\
\hline hormonal status & $-0.13 \pm 0.11$ & 0.237 & $0.03 \pm 0.02$ & 0.247 & $0.86 \pm 4.9$ & 0.861 & $-0.87 \pm 0.26$ & 0.001 \\
\hline PFDoA & $0.29 \pm 0.13$ & 0.024 & $-0.01 \pm 0.03$ & 0.761 & $-1.5 \pm 5.4$ & 0.779 & $-0.73 \pm 0.29$ & 0.012 \\
\hline sampling date & $0.26 \pm 0.14$ & 0.066 & $0.01 \pm 0.03$ & 0.625 & $-10.9 \pm 5.6$ & 0.052 & $-0.10 \pm 0.30$ & 0.736 \\
\hline sampling time & $-0.18 \pm 0.10$ & 0.088 & $0.03 \pm 0.02$ & 0.199 & $14.1 \pm 4.9$ & 0.004 & $0.21 \pm 0.26$ & 0.421 \\
\hline body mass & $-0.20 \pm 0.11$ & 0.076 & $-0.02 \pm 0.03$ & 0.343 & $4.9 \pm 5.6$ & 0.378 & $-0.16 \pm 0.28$ & 0.563 \\
\hline body size & $-0.02 \pm 0.11$ & 0.833 & $0.02 \pm 0.02$ & 0.325 & $-7.2 \pm 5.0$ & 0.148 & $0.14 \pm 0.25$ & 0.574 \\
\hline hormonal status & $-0.14 \pm 0.10$ & 0.176 & $0.03 \pm 0.02$ & 0.220 & $0.21 \pm 4.8$ & 0.965 & $-0.95 \pm 0.25$ & $<0.001$ \\
\hline PFTriA & $0.30 \pm 0.14$ & 0.036 & $0.00 \pm 0.03$ & 0.923 & $2.0 \pm 5.9$ & 0.735 & $-0.58 \pm 0.32$ & 0.064 \\
\hline sampling date & $0.26 \pm 0.15$ & 0.075 & $0.02 \pm 0.03$ & 0.597 & $-8.8 \pm 6.1$ & 0.153 & $-0.12 \pm 0.34$ & 0.725 \\
\hline sampling time & $-0.18 \pm 0.11$ & 0.094 & $0.03 \pm 0.02$ & 0.214 & $14.5 \pm 5.1$ & 0.004 & $0.10 \pm 0.27$ & 0.725 \\
\hline body mass & $-0.26 \pm 0.11$ & 0.026 & $-0.02 \pm 0.03$ & 0.368 & $5.7 \pm 5.5$ & 0.299 & $-0.08 \pm 0.28$ & 0.763 \\
\hline body size & $-0.06 \pm 0.12$ & 0.632 & $0.02 \pm 0.02$ & 0.348 & $-7.9 \pm 5.2$ & 0.124 & $0.20 \pm 0.27$ & 0.454 \\
\hline hormonal status & $-0.14 \pm 0.11$ & 0.181 & $0.03 \pm 0.02$ & 0.226 & $-0.13 \pm 4.9$ & 0.979 & $-0.92 \pm 0.26$ & $<0.001$ \\
\hline PFTeA & $0.33+0.11$ & 0.003 & $-0.02+0.03$ & 0.482 & $7.4+5.4$ & 0.171 & $-0.65+0.29$ & 0.028 \\
\hline sampling date & $0.22 \pm 0.12$ & 0.070 & $0.01 \pm 0.02$ & 0.4664 & $\frac{1.4 \pm-4.4}{-7.4 \pm 5.1}$ & 0.145 & $0.05 \pm 0.29$ & 0.020 \\
\hline sampling time & $-0.27 \pm 0.11$ & 0.013 & $0.03 \pm 0.02$ & 0.149 & $12.3 \pm 5.0$ & 0.015 & $0.40 \pm 0.27$ & 0.144 \\
\hline body mass & $-0.25 \pm 0.11$ & 0.018 & $-0.03 \pm 0.03$ & 0.317 & $6.4 \pm 5.3$ & 0.227 & $-0.05 \pm 0.28$ & 0.858 \\
\hline body size & $-0.05 \pm 0.11$ & 0.668 & $0.03 \pm 0.02$ & 0.275 & $-9.0 \pm 5.0$ & 0.072 & $0.19 \pm 0.26$ & 0.461 \\
\hline hormonal status & $-0.19 \pm 0.10$ & 0.062 & $0.03 \pm 0.02$ & 0.171 & $-1.9 \pm 4.9$ & 0.704 & $-0.84 \pm 0.27$ & 0.001 \\
\hline
\end{tabular}




\section{Figure captions}

619 Figure 1. Mean estimates of effect size and 95\% confidence interval are shown. These 620 were calculated from the statistical outcomes showing the effect of each PFAS congener

621 on protein oxidative damage. Estimates are positive when values of damage are higher in 622 birds having higher plasma concentration of a given PFAS congener. Note that effect size 623 estimates are significant when the $95 \%$ confidence interval does not include zero. 624 Numbers in bracket indicate carbon-chain-length of each PFAS congener.

625

626 Figure 2. Mean estimates of effect size and 95\% confidence interval were calculated from 627 the statistical outcomes showing the effect of each PFAS congener on plasma nonenzymatic micromolecular antioxidant capacity. Estimates are negative when values of 629 antioxidants are lower in birds having higher plasma concentration of a given PFAS 630 congener. Note that effect size estimates are significant when the $95 \%$ confidence interval 631 does not include zero. Numbers in bracket indicate carbon-chain-length of each PFAS 632 congener. 


$\begin{array}{lll}\text { PFOSlin (8) } & 0.06[-0.50,0.63] \\ \text { PFNA (9) } & 0.05[-0.51,0.62] \\ \text { PFDcA (10) } & 0.46[-0.12,1.04] \\ \text { PFUnA (11) } & 0.31[-0.26,0.88] \\ \text { PFDoA (12) } & 0.66[0.06,1.25] \\ \text { PFTriA (13) } & & 0.61[0.01,1.20] \\ \text { PFTeA (14) } & -2.25 & 0.92[0.29,1.54]\end{array}$

635

636 Figure 1

637 


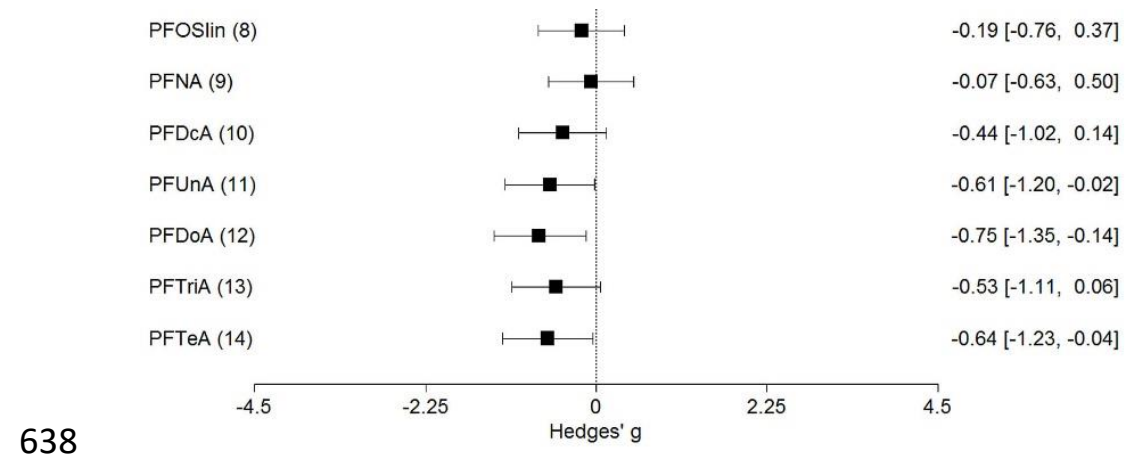

639 Figure 2 